\title{
Evaluating complementary networks of restoration plantings for landscape-scale occurrence of temporally-dynamic species
}

Karen Ikin ${ }^{1,2}$, Ayesha Tulloch ${ }^{1,2}$, Philip Gibbons ${ }^{1}$, Dean Ansell ${ }^{1}$, Julian Seddon ${ }^{3}$ and David Lindenmayer ${ }^{1,2}$

${ }^{1}$ Fenner School of Environment and Society, The Australian National University, Frank Fenner Building 141, Linnaeus Way, Acton ACT 2601, Australia

${ }^{2}$ ARC Centre of Excellence for Environmental Decisions, The Australian National University, Frank Fenner Building 141, Linnaeus Way, Acton ACT 2601, Australia

${ }^{3}$ Environment Division, Environment and Planning Directorate, ACT Government, Building 3, 9 Sanford St., Mitchell, Canberra ACT 2601, Australia

Correspondence: karen.ikin@anu.edu.au Fenner School of Environment and Society, The Australian National University, Linnaeus Way, Acton ACT 2601, Australia

Article type: Research article, Conservation Biology

Word count: 282 abstract, 5939 main text and references

Keywords: agri-environmental schemes, complementarity, dynamic distributions, Marxan, spatial prioritisation, systematic conservation planning, vegetation restoration, woodland birds

Acknowledgements: We thank the Australian Research Council, the Murray and Riverina Local Land Services, and the Caring for Our Country Program for funding for this project. We thank D. Michael, M. Crane, S. Okada, C. MacGregor, L. McBurney, D. Blair and D. Florence for their important contribution to the collection of the field data, and C. Foster and the Conservation and Landscape Ecology Group for discussion of ideas. 


\section{Abstract}

2 Multi-billion dollar investments in land restoration make it critical that conservation goals are achieved cost-

3 effectively. Approaches developed for systematic conservation planning offer opportunities to evaluate

4 landscape-scale, temporally-dynamic biodiversity outcomes from restoration, improving on traditional

5 approaches of focusing on the most species-rich plantings. We investigated whether it is possible to apply a

6 complementarity-based approach to evaluate the extent to which an existing network of restoration plantings meets representation targets. Using a case study of woodland birds of conservation concern in southeastern

8 Australia, we compared complementarity-based selections of plantings based on temporally-dynamic species

9 occurrences with (1) selections based on static species occurrences, and (2) selections based on ranking

10 plantings by species richness. We found that incorporating dynamics in species occurrences across a five-year

11 period resulted in higher species occurrences and proportion of targets met compared with using species

12 occurrences taken at a single point in time. For equivalent cost, the dynamic complementarity approach also

13 always resulted in higher average minimum percent occurrence of species maintained through time and a

14 higher proportion of the bird community meeting representation targets compared with the species richness

15 approach. Plantings selected under the complementarity approaches represented the full range of planting 16 attributes, whilst those selected under the species richness approach were larger in size. Future restoration

17 policy should not attempt to achieve all conservation goals within individual plantings, but should instead

18 capitalise on restoration opportunities as they arise to achieve collective value of multiple plantings across the

19 landscape. Networks of restoration plantings with complementary attributes of age, size, vegetation structure,

20 and landscape context lead to considerably better outcomes than conventional restoration objectives of site-

21 scale species richness, and are crucial for allocating restoration investment wisely to reach desired

22 conservation goals. 


\section{Introduction}

Restoration plantings are a widely implemented biodiversity conservation approach in agricultural landscapes (Bullock et al. 2011). Worldwide, international biodiversity targets for 2020 include the restoration of at least $15 \%$ of degraded ecosystems (Aichi Biodiversity Target 15, CBD COP 2010). Similar international targets for the restoration of 150 million ha of degraded lands by 2020 (Rio+20, UNCSD 2012) are estimated to cost nations globally US\$18 billion per year (Menz et al. 2013). Specific restoration targets have been set by the European Union (Bullock et al. 2011) and individual countries, including Australia, whose Biodiversity Fund aims to restore 18 million ha of native vegetation by 2020 with a budget of US $\$ 1$ billion (Australian Government 2013). Given this substantial investment, it is important that restoration initiatives are both efficient and cost-effective, maximising biodiversity outcomes for the least cost (Menz et al. 2013).

Most research on biodiversity outcomes within restoration plantings (a form of active restoration) has focused on whether and how individual plantings achieve high species occurrence, richness or abundance (Munro et al. 2007). In addition to comparing the value of restoration plantings to that of reference sites (e.g. Gould et al. 2013), these studies have identified attributes of plantings that contribute to increased biodiversity at the sitescale, including planting age (Vesk et al. 2008), area and shape (Lindenmayer et al. 2010; Jellinek et al. 2014) and vegetation structure (Munro et al. 2011). This earlier research recommends that future restoration investment be focused on maximising site-scale attributes related to high individual planting biodiversity. Restoration plantings, however, also have value at the landscape scale (Thomson et al. 2009; Rappaport et al. 2015), and the collective features of different plantings across the landscape may be a better measure of biodiversity value than site-scale attributes. An alternative approach to restoration investment, therefore, is to maximise the number of species present across the entire landscape through a focus on networks of restoration plantings.

Systematic conservation planning, originally developed for locating and designing cost-effective protected areas (Margules \& Pressey 2000), has increasingly been used to spatially prioritise new areas for restoration (Thomson et al. 2009; Lethbridge et al. 2010; McBride et al. 2010; Wilson et al. 2011; Yoshioka et al. 2014; Possingham et al. 2015). A key concept is complementarity, which ensures that each restoration planting 
contributes unrepresented features to the larger network of plantings (i.e. that each planting complements the others in the network) (Margules \& Pressey 2000). Complementarity approaches to the selection of restoration plantings thus differ from selection based on traditional measures of conservation value that focus on the most species-rich plantings. This is because plantings with high individual species richness may not necessarily contribute to overall conservation goals of maximising diversity at a landscape or regional scale (Margules \& Pressey 2000; see also Chadès et al. 2015). Systematic conservation planning has frequently been used to evaluate the performance of an existing set of protected areas (e.g. Stewart et al. 2003), and the same approach might be useful to evaluate the performance of an existing network of restoration plantings. Undertaking such an evaluation would: (a) identify the best complementary subset of plantings that contribute the most to the biodiversity benefits of the network, and might be afforded protection in cases of impact assessment and future landscape clearing, and (b) elucidate the attributes of plantings important for landscape-scale biodiversity outcomes. In doing so, landscapes undergoing restoration might have more efficient investment and conservation outcomes.

Most systematic conservation planning usually considers species occurrence only at a single point in time, but plant and animal communities (particularly those in disturbed landscapes) are temporally dynamic (Grantham et al. 2011; Runge et al. 2014; Tulloch et al. 2016). Failure to incorporate dynamics into spatial prioritisations - e.g. using static species distributions derived from a single year of data or pooled over years - can lead to insufficient representation of species over time (Runge et al. 2016; Tulloch et al. 2016). Whist previous spatial prioritisations for restoration have considered dynamics in the age and structural complexity of restored vegetation (e.g. Thomson et al. 2009), we are not aware of any spatial prioritisation study that has accounted for temporal dynamics in the distribution or occurrence of species colonising restoration plantings, potentially undermining the success of restoration schemes.

In this study, we investigated whether taking a temporally-dynamic complementarity approach can evaluate the contribution of existing restoration plantings to achieve landscape-scale species occurrence. We used, as a case study, a network of plantings in the South West Slopes Bioregion of southeastern Australia. Only 15\% of the once extensive temperate eucalypt woodland remains within this agricultural region (Benson 2008) and, 
81 consequently, many woodland bird species are of conservation concern (Rayner et al. 2014). Since 1990,

82 however, concerted investment has been made in establishing restoration plantings for a range of conservation

83 and land management objectives, including increasing woodland bird habitat. Through extensive programs managed by multiple stakeholders, thousands of hectares of vegetation have been planted, corresponding to increases of 3-4\% of vegetation cover in the landscape (Lindenmayer et al. 2012; Cunningham et al. 2014). As part of the South West Slopes Restoration Study (Cunningham et al. 2007), 61 plantings have been surveyed for birds and vegetation in five spring seasons since 2006.

Our first aim in this study was to find the best complementary network (i.e. subset) of established restoration plantings to support landscape-scale occurrence of species of conservation concern for minimal establishment cost. We accounted for temporally dynamic species occurrences, by requiring representation targets for species occurrence to be met in every year (Runge et al. 2016). We compared the outcomes of taking a dynamic complementarity approach to find a network of plantings that met our desired representation target with (1) networks selected using a static complementarity approach based on single years of data, and (2) equivalently costed networks of plantings ranked by richness of species of conservation concern.

97 Our second aim was to identify the attributes of plantings that contributed most to the landscape-scale occurrence of species of conservation concern. The plantings in our study were established for a variety of reasons (e.g. wind breaks, soil erosion and salinity), varied in age, area, shape, vegetation structure, and landscape context, and subsequently varied in their individual value for woodland birds (Lindenmayer et al. 2010). This opportunistically created a network of a plantings that was ideal for exploring how subsets of plantings with different characteristics differed in terms of their ability to represent all bird species of conservation concern. Our study thus quantifies the value of evaluating biodiversity benefits of management at the landscape scale and incorporating temporally dynamic species distributions into restoration planning. restoration landscapes. 


\section{Methods}

Study area, experimental design, and data collection

The South-West Slopes Restoration Study is located in a $150 \mathrm{~km}$ x $120 \mathrm{~km}$ area of the South West Slopes Bioregion of New South Wales, Australia (Fig. 1). This region was once dominated by temperate box-gum Eucalyptus woodland, but is now characterised by cropping and livestock grazing. Farms typically have between 3\% and 35\% native vegetation cover, including old growth woodland, regrowth, and plantings (Cunningham et al. 2014). For this investigation, we used data from 61 plantings, distributed across 25 farms. These plantings were not established following any plant species composition or spacing protocols but, typically, planting composition was a mix of local endemic and exotic Australian ground cover, understorey and overstorey species, with plants spaced $\sim 2 \mathrm{~m}$ apart. For each planting, we compiled data on variables known to be important for bird richness and occurrence in restoration plantings: years since establishment, area and width of plantings, vegetation structural complexity, surrounding woody vegetation cover (a proxy for connectivity), and landscape position (see Table S1 and S2 in the Supporting Information).

We used the area and shape of plantings to estimate the total establishment cost of each planting. Our estimates were based on 2015 pricing rates used by Greening Australia, one of Australia's largest and longestrunning restoration practitioners. We calculated costs (\$AUD) of materials and labour for fencing and directseeding of sites (Table S3). As our focus was on biodiversity as a public benefit, we considered only public costs of establishing restoration sites in this analysis. We acknowledge the importance of considering private opportunity costs and ongoing management costs in conservation planning on public land, but the inclusion of such information was beyond the scope of this study.

We collected bird occurrence data in the spring seasons of 2006, 2008, 2009, 2011 and 2013. In each year, every planting was visited twice within a four day period in early November, on two days by different observers, and a five-minute point count was conducted at the $0 \mathrm{~m}, 100 \mathrm{~m}$ and $200 \mathrm{~m}$ points of a permanent transect. All birds seen or heard within $50 \mathrm{~m}$ of the point, excluding those flying overhead, were recorded as present. Surveys were conducted between sunrise and mid-morning, avoiding inclement weather. This strict survey protocol is designed to address biases in observer heterogeneity (Cunningham et al. 1999) and false- 
negative errors, i.e. failure to detect species that are present (Banks-Leite et al. 2014), and is applied across all our long-term major studies in woodlands.

We defined woodland birds of conservation concern as those species: (i) dependent on woodland for foraging and/or nesting (Silcocks et al. 2005), and (ii) listed as threatened in New South Wales under the Threatened Species Conservation Act 1995 (this also captures relevant nationally-listed threatened species) and/or identified as having a $>20 \%$ decrease in South West Slopes bioregion reporting rate between the first and second Atlas of Australian Birds (Barrett et al. 2003). Excluding very rare species (only recorded once during the five years), this definition resulted in 26 species of conservation concern for analysis (Table S4). We used Permutational Multivariate Analysis of Variance (PERMANOVA) to test for significant differences in species composition between years, based on a Bray-Curtis dissimilarity matrix adjusted for species presence/absence data, using the vegan package in $\mathrm{R}$ ( $\mathrm{R}$ Development Core Team 2007).

\section{Data analysis}

To address our first aim (i.e. achieve targets of landscape-scale occurrence of species of conservation concern for least investment), we compared the outcomes of using 'dynamic' versus 'static' complementarity approaches, and 'complementarity' versus 'ranked' approaches, to find the best subset network of restoration plantings. We set an objective of representing targets of $10 \%$ to $100 \%$ (10\% increments) occurrence of each species per year in all years (equivalent to $10 \%$ to $100 \%$ of plantings where each species occurred in each year).

To find the best complementarity-based networks of plantings for each target, we used the decision-support software, Marxan, which uses a simulated annealing algorithm to solve the minimum set problem (Ball et al. 2009). The objective was to minimise resources expended (i.e. cost of the planting network) whilst meeting pre-specified representation targets (i.e. scenarios of $10 \%$ to $100 \%$ individual species occurrence per year in all years). To account for temporal variation in species occurrence between plantings (planning units), we created a conservation feature for each species for each survey year (five conservation features per species of conservation concern, giving 130 conservation features in total), following Runge et al. (2016). 
164 Representation of conservation features in a given planting was based on presence/absence data, i.e. whether 165 or not each species was recorded in each planting in each year. For each increasing $10 \%$ target scenario, we 166 compared the 'dynamic' approach with five 'static' approaches, based on single years of data (2006 only, 1672008 only, 2009 only, 2011 only, and 2013 only). The objective of the static approaches was to meet representation targets only for that particular year. We parameterised Marxan to find the most cost-effective network irrespective of spatial configuration (by setting the boundary length modifier to zero), and performed 100 runs per scenario. We confirmed that the selected networks were not driven by planting cost by comparing the scenarios with baseline 'no cost' scenarios (Table S5). We considered two Marxan outputs for

172 each scenario: the 'best' network of plantings that met the representation target for the least cost, and the 173 'selection frequency' (i.e. irreplaceability) of each planting (the number of times each planting was selected across the 100 runs). For our scenarios, these two values were strongly positively correlated $(\geq 0.9)$, and the average selection frequency for plantings selected in the best network was close to $100 \%$ (Table S6). Because this indicates high irreplaceability in selected plantings, we used the 'best' networks of plantings for subsequent analyses.

We paired each dynamic complementarity scenario with a ranked scenario of equivalent cost, creating ten matched pairs of networks (i.e. one for each species occurrence target (10\% to $100 \%)$ ). To do this, we calculated total richness of species of conservation concern across the five survey years and ranked individual plantings from high to low species richness. We calculated the cumulative cost of the plantings based on these rankings, and included in the best network only those plantings that could be afforded for less than or equal to the cost of the dynamic complementarity scenario.

For each network selected by the dynamic, static, and ranked approaches, we calculated the: (i) cumulative establishment cost, (ii) number of plantings in the network, and (iii) summary statistics for the minimum percentage of the occurrence of each species that was met over the five years. We also calculated Bray-Curtis dissimilarity (adjusted for presence/absence data) between networks to assess spatial concordance between the selected plantings (e.g. low Bray-Curtis dissimilarity between a pair of networks indicates that the spatial locations of the plantings in the networks were similar). We confirmed that differences between the dynamic 
complementarity and ranked networks were not driven by cost-effectiveness by comparing our results with equivalently-costed networks that were based on ranking plantings by cost-effectiveness but ignoring complementarity (dividing species richness by cost) (Table S8).

To address our second aim (i.e. identify the attributes of plantings that contribute to landscape-scale occurrence of species of conservation concern), we modelled the relationship between planting attributes and the probability of the planting being selected in the dynamic and static complementarity and ranked scenarios for two representation targets (30\% and $60 \%$ species occurrence in all years). We also modelled the number of times (frequency) each planting was selected in the static networks for these targets over the five years. The first target (30\% occurrence) was chosen to reflect typical targets for conservation assessments (Svancara et al. 2005). The second target (60\% occurrence) was chosen based on the results of the Marxan analyses, as there was a threshold jump in planting benefits at this target level for the dynamic complementarity approach. Planting attributes included standardised site-level variables (Table S1). Planting width was strongly and positively correlated with planting area, and so was excluded from further analyses We adopted an information theoretic approach to model selection (Burnham \& Anderson 2002), and compared a candidate set of 31 models that included single and additive combinations of all planting attributes (Table 2). We considered the univariate planting area model to be the null model, as previous research suggests that this attribute is of primary importance in restoration (e.g. Lindenmayer et al. 2010). We fitted generalised linear models (GLM), with a binomial error distribution and log link (AICcmodavg package).We modelled each response variable against a distance-weighted spatial autocovariate (spdep package) to check for spatial autocorrelation between sites. For response variables that showed evidence of spatial autocorrelation, we included the distance-weighted spatial autocovariate in each alternative model. We ranked the candidate set of models by Akaike's Information Criterion corrected for small sample bias (AICc). For top-ranked models (within $2 \triangle \mathrm{AICc}$ of the model with the lowest AICc), we assessed model support using Nagelkerke's coefficient of determination ( $\mathrm{R}^{2}$; fms $b$ package), and calculated model-averaged effect sizes for the model terms. 


\section{Results}

220 Over the five survey years, we recorded 100 woodland bird species, including 26 of conservation concern

221 (Table S4). Total richness of species of conservation concern ranged from 1 to 14 species per planting.

222 Species composition differed significantly between years $(\mathrm{F}=2.723, p=0.006)$.

Dynamic vs static complementary restoration planting networks

225 The complementarity approach that incorporated dynamic species occurrences consistently resulted in higher

226 mean minimum percent occurrence of species across the five survey years than the static complementarity 227 approaches based on single years of data (Fig. 2a, Table S7). Although more expensive to achieve any given 228 target than the static approaches, the dynamic approach always met the representation target for every species 229 (Fig. 2b). In comparison, although plantings selected using a static single-year approach met the representation target for that year, they failed to meet the representation target across all time (2006-2013) for more than a third of species. This is because all 61 plantings were required to meet the dynamic representation target of 100\% occurrence for each species across all time, compared with between 42 and 54 plantings for the 233 static targets.

The spatial locations of the best network of selected plantings differed markedly between years. For example, for the $30 \%$ target, there was $44 \%-78 \%$ Bray-Curtis dissimilarity in selected plantings between years

237 (Table 1). To meet this target, each planting was selected an average of 1.46 times (out of 5 possible static networks); 20 plantings were never selected and only one planting was always selected. The spatial locations

242 between increments $=12 \%$ ).

\section{Dynamic complementary vs ranked restoration planting networks}

245 The dynamic-complementarity approach consistently resulted in higher mean percent species occurrence than 246 the species-richness ranked approach (Fig. 3a, Table S8). For equivalent cost, mean minimum percent 
occurrence of species was up to $30 \%$ higher in the complementarity scenarios. Further, whilst the

representation target was achieved in every complementarity scenario (i.e. all species met the specified target), up to $46 \%$ of species did not meet the target in the equivalent-costed ranked scenarios (Fig. $3 \mathrm{~b}$ ). On average, there was $78 \%$ overlap in the spatial location of plantings selected under the complementarity and ranked approaches (average Bray-Curtis dissimilarity $=22 \%$ ).

\section{Relationships with planting attributes}

Plantings selected under the static and dynamic complementarity approach for the $30 \%$ and $60 \%$ targets did not consistently differ in their attributes from the non-selected plantings. Model uncertainty was high, as topranked models had relatively low $\mathrm{R}^{2}$ values (Table 2). The effect sizes of terms in the models were generally small and variable (confidence intervals crossed 0) (Fig. 4a - c, Fig. S1). Similarly, there was no consistent relationship between the number of times each planting was selected in the static networks over the five years and planting attributes (Fig. 4d). Plantings selected more frequently to meet the $30 \%$ target were younger and surrounded by more woody vegetation cover but effect sizes were small, and these effects were variable for plantings selected to meet the $60 \%$ target. In comparison, plantings selected under the richness ranked scenarios were larger than non-selected plantings, and model certainty was relatively high (Table 2, Fig. 4e).

\section{Discussion}

The restoration of degraded lands is an international conservation goal, with multi-billion dollar annual investment, requiring wise allocation of resources (Bullock et al. 2011; Menz et al. 2013). Our study shows that it is possible to apply the principles of systematic conservation planning to evaluate the extent to which an existing network of restoration plantings meets representation targets for woodland birds of conservation concern. Incorporating dynamics in species occurrences across a five-year period resulted in higher species occurrences and proportion of targets met compared with using species occurrences representing a single point in time. Importantly, we found that for equivalent cost, the dynamic complementarity approach always resulted in higher average minimum percent occurrence of species maintained through time and a higher proportion of the bird community meeting representation targets compared with ranking plantings by species richness (Aim 1). We also found that plantings selected to achieve goals of both representation and 
291

complementarity represented the full range of planting attributes, whilst those selected under the richness approach were larger in size (Aim 2).

We found that incorporating dynamic species occurrences led to more expensive networks of restoration plantings, but considerably higher long-term species occurrences and achievement of representation targets compared with static approaches. This was because the bird community was highly spatially and temporally dynamic, with little overlap between networks selected based on single years of data. Compared with static distribution approaches, incorporating temporally-dynamic species ranges in systematic conservation planning leads to more expensive and less flexible networks, but improved biodiversity outcomes (see also Grantham et al. 2011; Lourival et al. 2011; Van Teeffelen et al. 2012). For example, Runge et al. (2016), found that accounting for annual and seasonal range variation in nomadic bird species led to greater areas of land needing to be conserved to achieve targets but greater levels of species protection. Similarly, in their case study of the South American Pantanal wetlands, Lourival et al. (2011) found that incorporating dynamic vegetation distributions, although increasing expense, improved the reliability and long-term adequacy of their reserve networks. A dynamic prioritisation approach is thus crucial for allocating investment wisely to reach desired conservation goals (Tulloch et al. 2016).

Using a landscape-scale complementarity approach was critical to achieve cost-effective subsets of restoration plantings across the existing network. For example, to achieve similar species representation (for targets $\leq 90 \%$ species occurrence), the complementarity approach required less investment, fewer plantings, and less combined restored area than the ranked approach based on site-scale species richness. Further, even with the substantial additional investment needed for the ranked approaches, many species still did not meet the representation target in every year (compared with all targets achieved under the complementarity approach). Complementarity approaches to reserve design have long been recognised as superior to ranked approaches (Chadès et al. 2015), and our study supports their utility in restoration programs (Yoshioka et al. 2014). However, by definition, the high efficiency that complementarity achieves may result in low redundancy across the network of restoration sites, with implications for network robustness to disturbance (O'Hanley et al. 2007). In our scenarios, we incorporated multiple years of data, including from severe drought (2006 - 
2009) and post-drought recovery (2011 - 2013). Incorporating these dynamics within our system likely reduced the trade-off between complementarity and robustness through accounting for stochastic processes (Lourival et al. 2011; Van Teeffelen et al. 2012).

Our finding that no single attribute makes plantings best for bird occupancy over space and time challenges conventional thinking that there is a type of restoration planting best for woodland birds (Lindenmayer et al. 2010). Instead, our findings support previous research on the differing and complementary habitat suitability of plantings for different functional groups (Loyn et al. 2007). By collectively considering occupancy of plantings by each species in our analyses, we were able to specifically account for the variable habitat requirements of our bird community. However, it is difficult to evaluate to what extent the bird occurrence patterns within the best networks of plantings were influenced by bird occurrence in unselected plantings (to which highly-mobile taxa like birds could disperse) or by other vegetation types (e.g. regrowth and remnant vegetation) in the study landscape (Lindenmayer et al. 2012). Future research should investigate complementarity and connectivity between restoration plantings, regrowth vegetation (i.e. passive restoration), and remnant vegetation for landscape-scale species persistence. Future research could also integrate dynamics in planting attributes with dynamics in species occurrences. For instance, in our study we held planting attributes constant, yet some attributes such as age, structural complexity, and connectivity may change through time (Thomson et al. 2009). As such, the attributes of plantings that are likely to maximise complementarity may also change through time, as suggested by our findings from our static models. Ideally, any future research that uses cost-effectiveness analysis to prioritise restored habitat in agricultural landscapes should also incorporate costs associated with lost farming opportunities in restored areas (Naidoo et al. 2006).

Translating our findings into future restoration policy involves some challenges. Our results show that it is desirable from a complementarity perspective to encourage a mixed portfolio of restoration projects that differ in the attributes of plantings and landscape context. Given real-world social, economic and political constraints on biologically-driven conservation planning 'informed opportunism' (sensu Noss et al. 2002) may be appropriate. That is, in addition to available biodiversity knowledge, future investment in restoration initiatives also should be guided by the capacity and willingness of land owners to participate (Knight et al. 
331 2010). A key difficulty is developing policy that can capitalise on informed opportunism to achieve

332 complementary planting networks. One approach may be to implement policies that support consistent,

333 incremental funding of restoration plantings in a region, so that a breadth of planting ages and structural

334 attributes is maintained. Another more resource-intensive approach could be to allocate funding for new

335 plantings that would complement the attributes of existing restoration plantings.

337 In summary, our study shows that a complementarity approach can be used to find the best network of 338 established restoration plantings, and that this network is more cost-effective and represents more of species' 339 landscape occupancy than a traditional species richness approach,. Further, incorporating temporally-dynamic 340 species occurrences leads to a more cost-effective and robust restoration plantings network compared with 341 using static single-year data (Grantham et al. 2011; Lourival et al. 2011; Van Teeffelen et al. 2012; Runge et 342 al. 2014). Substantial resources will continue to be invested in restoration initiatives in response to international and national policy, and as part of wider agri-environmental schemes (Bullock et al. 2011; Menz et al. 2013). This investment should not attempt to achieve all conservation goals within individual plantings, but could instead be implemented incrementally to capitalise on restoration opportunities as they arise (Noss et al. 2002) to achieve collective value of multiple plantings across the landscape. Adopting a landscape-scale temporally-dynamic approach leads to considerably better outcomes for a faunal community of conservation concern than applying conventional site-scale metrics, and is crucial for the wise allocation of restoration investment to reach desired conservation goals.

\section{Literature cited}

Australian Government. 2013. Biodiversity Fund.

\section{http://www.environment.gov.au/cleanenergyfuture/biodiversity-fund/.}

Ball, I. R., H. P. Possingham, and M. Watts. 2009. Marxan and relatives: Software for spatial conservation prioritisation. Pages 185-195 in A. Moilanen, K. A. Wilson, and H. P. Possingham, editors. Spatial conservation prioritisation: Quantitative methods and computational tools. Oxford University Press, Oxford, UK. 
Banks-Leite, C., R. Pardini, D. Boscolo, C. R. Cassano, T. Püttker, C. S. Barros, and J. Barlow. 2014. Assessing the utility of statistical adjustments for imperfect detection in tropical conservation science. J Appl Ecol 51:849-859.

Barrett, G., A. Silcocks, S. Barry, R. Cunningham, and R. Poulter 2003. The new atlas of Australian birds. Royal Australasian Ornithologists Union, Hawthorn East.

Benson, J. 2008. New South Wales Vegetation Classification and Assessment: Part 2 Plant communities of the NSW South-western Slopes Bioregion and update of NSW Western Plains plant communities, Version 2 of the NSWVCA database. Cunninghamia 104:599-673.

Bullock, J. M., J. Aronson, A. C. Newton, R. F. Pywell, and J. M. Rey-Benayas. 2011. Restoration of ecosystem services and biodiversity: conflicts and opportunities. Trends Ecol Evol 26:541-549.

Burnham, K. P., and D. R. Anderson 2002. Model selection and multimodel inference. Springer, New York. CBD COP. 2010. Decision adopted by the Conference of the Parties to the Convention on Biological Diversity at its Tenth Meeting X/2. The Strategic Plan for Biodiversity 2011-2020 and the Aichi Biodiversity Targets. https://www.cbd.int/sp/targets/default.shtml.

Chadès, I., S. Nicol, S. van Leeuwen, B. Walters, J. Firn, A. Reeson, T. G. Martin, and J. Carwardine. 2015. Benefits of integrating complementarity into priority threat management. Conserv Biol 29:525-536.

Cunningham, R., D. B. Lindenmayer, D. Michael, M. Crane, P. S. Barton, P. Gibbons, S. Okada, K. Ikin, and J. A. R. Stein. 2014. The law of diminishing returns: woodland birds respond to native vegetation cover at multiple spatial and temporal scales Divers Distrib 20:59-71.

Cunningham, R. B., D. B. Lindenmayer, H. A. Nix, and B. D. Lindenmayer. 1999. Quantifying observer heterogeneity in bird counts. Austral Ecol 24:270-277.

Cunningham, R. B., D. B. Lindenmayer, M. Crane, D. Michael, and C. MacGregor. 2007. Reptile and arboreal marsupial response to replanted vegetation in agricultural landscapes. Ecol Appl 17:609-619.

Gould, R. K., L. Pejchar, S. G. Bothwell, B. Brosi, S. Wolny, C. D. Mendenhall, and G. Daily. 2013. Forest Restoration and Parasitoid Wasp Communities in Montane Hawai'i. PLoS ONE 8:e59356.

Grantham, H. S., E. T. Game, A. T. Lombard, A. J. Hobday, A. J. Richardson, L. E. Beckley, R. L. Pressey, J. A. Huggett, J. C. Coetzee, C. D. van der Lingen, S. L. Petersen, D. Merkle, and H. P. Possingham. 
2011. Accommodating Dynamic Oceanographic Processes and Pelagic Biodiversity in Marine Conservation Planning. PLoS ONE 6:e16552.

Jellinek, S., K. M. Parris, M. A. McCarthy, B. A. Wintle, and D. A. Driscoll. 2014. Reptiles in restored agricultural landscapes: the value of linear strips, patches and habitat condition. Anim Conserv 17:544-554.

Knight, A. T., R. M. Cowling, M. Difford, and B. M. Campbell. 2010. Mapping Human and Social Dimensions of Conservation Opportunity for the Scheduling of Conservation Action on Private Land. Conserv Biol 24:1348-1358.

Lethbridge, M. R., M. I. Westphal, H. P. Possingham, M. L. Harper, N. J. Souter, and N. Anderson. 2010. Optimal restoration of altered habitats. Environmental Modelling \& Software 25:737-746.

Lindenmayer, D. B., E. J. Knight, M. J. Crane, R. Montague-Drake, D. R. Michael, and C. I. MacGregor. 2010. What makes an effective restoration planting for woodland birds? Biol Conserv 143:289-301.

Lindenmayer, D. B., A. R. Northrop-Mackie, R. Montague-Drake, M. Crane, D. Michael, S. Okada, and P. Gibbons. 2012. Not all kinds of revegetation are created equal: Revegetation type influences bird assemblages in threatened australian woodland ecosystems. PLOS ONE 7: e34527.

Lourival, R., M. Drechsler, M. E. Watts, E. T. Game, and H. P. Possingham. 2011. Planning for reserve adequacy in dynamic landscapes; maximizing future representation of vegetation communities under flood disturbance in the Pantanal wetland. Divers Distrib 17:297-310.

Loyn, R. H., E. G. McNabb, P. Macak, and P. Noble. 2007. Eucalypt plantations as habitat for birds on previously cleared farmland in south-eastern Australia. Biol Conserv 137:533-548.

Margules, C. R., and R. L. Pressey. 2000. Systematic conservation planning. Nature 405:243-253.

McBride, M. F., K. A. Wilson, J. Burger, Y.-C. Fang, M. Lulow, D. Olson, M. O’Connell, and H. P. Possingham. 2010. Mathematical problem definition for ecological restoration planning. Ecol Modell 221:2243-2250.

Menz, M. H. M., K. W. Dixon, and R. J. Hobbs. 2013. Hurdles and Opportunities for Landscape-Scale Restoration. Science 339:526-527. 
411 Munro, N., J. Fischer, G. Barrett, J. Wood, A. Leavesley, and D. B. Lindenmayer. 2011. Bird's response to revegetation of different structure and floristics - are "restoration plantings" restoring bird communities. Restor Ecol 19:223-235.

Munro, N. T., D. B. Lindenmayer, and J. Fischer. 2007. Faunal response to revegetation in agricultural areas of Australia: A review. Ecological Management and Restoration 8:199-207.

Naidoo, R., A. Balmford, P. J. Ferraro, S. Polasky, T. H. Ricketts, and M. Rouget. 2006. Integrating economic costs into conservation planning. Trends Ecol Evol 21:681-687.

Noss, R. F., C. Carroll, K. Vance-Borland, and G. Wuerthner. 2002. A Multicriteria Assessment of the Irreplaceability and Vulnerability of Sites in the Greater Yellowstone Ecosystem. Conserv Biol 16:895-908.

O’Hanley, J. R., R. L. Church, and J. K. Gilless. 2007. The importance of in situ site loss in nature reserve selection: Balancing notions of complementarity and robustness. Biol Conserv 135:170-180.

Possingham, H. P., M. Bode, and C. J. Klein. 2015. Optimal Conservation Outcomes Require Both Restoration and Protection. PLoS Biol 13:e1002052.

R Development Core Team. 2007. R: A language and environment for statistical computing. R Foundation for Statistical Computing.

Rappaport, D. I., L. R. Tambosi, and J. P. Metzger. 2015. A landscape triage approach: combining spatial and temporal dynamics to prioritize restoration and conservation. $J$ Appl Ecol:n/a-n/a.

Rayner, L., D. Lindenmayer, P. Gibbons, and A. D. Manning. 2014. Evaluating empirical evidence for decline in temperate woodland birds: a nationally threatened assemblage of species. . Biol Conserv 171:145155.

Runge, C. A., T. G. Martin, H. P. Possingham, S. G. Willis, and R. A. Fuller. 2014. Conserving mobile species. Front Ecol Environ 12:395-402.

Runge, C. A., A. Tulloch, H. Possingham, V. Tulloch, and R. A. Fuller. 2016. Incorporating dynamic distributions into spatial prioritization. Diversity \& Distributions:DOI: 10.1111/ddi.12395.

Silcocks, A., C. Tzaros, M. Weston, and P. Olsen. 2005. An interim guild classification for woodland and grassland birds in Australia. Birds Australia Supplementary Report to State of the Environment Report 2006, Carlton. 
439 Stewart, R., T. Noyce, and H. Possingham. 2003. Opportunity cost of ad hoc marine reserve design decisions: an example from South Australia. Mar Ecol Prog Ser 253:25-38.

441 Svancara, L. K., R. Brannon J., M. Scott, C. R. Groves, R. F. Noss, and R. L. Pressey. 2005. Policy-driven versus Evidence-based Conservation: A Review of Political Targets and Biological Needs. Bioscience 55:989-995.

444 Thomson, J. R., A. J. Moilanen, P. A. Vesk, A. F. Bennett, and R. M. Nally. 2009. Where and when to 445 revegetate: a quantitative method for scheduling landscape reconstruction. Ecol Appl 19:817-828.

Tulloch, A. I. T., I. Chadés, Y. Dujardin, M. J. Westgate, P. W. Lane, and D. Lindenmayer. 2016. Dynamic species co-occurrence networks require dynamic biodiversity surrogates. Ecography:doi: 10.1111/ecog.02143.

UNCSD. 2012. United Nations Rio+20 Conference on Sustainable Development Dialogues. http://vote.riodialogues.org/.

Van Teeffelen, A. J. A., C. C. Vos, and P. Opdam. 2012. Species in a dynamic world: Consequences of habitat network dynamics on conservation planning. Biol Conserv 153:239-253.

453 Vesk, P. A., R. Nolan, J. R. Thomson, J. W. Dorrough, and R. M. Nally. 2008. Time lags in provision of habitat resources through revegetation. Biol Conserv 141:174-186.

Wilson, K. A., M. Lulow, J. Burger, Y.-C. Fang, C. Andersen, D. Olson, M. O’Connell, and M. F. McBride. 2011. Optimal restoration: accounting for space, time and uncertainty. $J$ Appl Ecol 48:715-725.

Yoshioka, A., M. Akasaka, and T. Kadoya. 2014. Spatial Prioritization for Biodiversity Restoration: A Simple Framework Referencing Past Species Distributions. Restor Ecol 22:185-195. 


\section{Tables and Figures}

Table 1: Percent Bray-Curtis dissimilarity between the spatial locations of plantings selected in the static and dynamic complementarity restoration planting networks for the $30 \%$ representation target.

\begin{tabular}{l|rrrrr}
\hline & 2006 & 2008 & 2009 & 2011 & 2013 \\
\hline 2008 & 44.44 & & & & \\
2009 & 52.94 & 57.89 & & & \\
2011 & 54.29 & 48.72 & 78.38 & & \\
2013 & 43.75 & 50.00 & 58.82 & 54.29 & \\
Dynamic & 50.00 & 38.46 & 36.00 & 45.10 & 41.67 \\
\hline
\end{tabular}


Table 2: Candidate set of models. Nagelkerke's coefficient of determination $\left(\mathrm{R}^{2}\right)$ is presented for the top-ranked models $\left(\Delta \mathrm{AICc}{ }^{\mathrm{a}} \leq 2\right)$. 'Area' is planting area, 'Age' is years since planting establishment, 'HCS' (habitat complexity score) represents vegetation structural complexity, 'Woody Veg' is percentage of vegetation cover within $1 \mathrm{~km}$, and 'TWI' (topographic wetness index) represents position in landscape ranging from ridges to valley floors.

\begin{tabular}{|c|c|c|c|c|c|c|c|c|c|c|c|c|c|c|c|c|}
\hline \multirow[t]{2}{*}{ Model } & \multicolumn{2}{|c|}{2006} & \multicolumn{2}{|c|}{2008} & \multicolumn{2}{|c|}{2009} & \multicolumn{2}{|c|}{2011} & \multicolumn{2}{|c|}{2013} & \multicolumn{2}{|c|}{ Dynamic } & \multicolumn{2}{|c|}{ Frequency $^{b}$} & \multicolumn{2}{|c|}{ Ranked } \\
\hline & $30 \%$ & $60 \%$ & $30 \%$ & $60 \%$ & $30 \%$ & $60 \%$ & $30 \%$ & $60 \%$ & $30 \%$ & $60 \%$ & $30 \%$ & $60 \%$ & $30 \%$ & $60 \%$ & $30 \%$ & $60 \%$ \\
\hline Area $^{c}$ & 0.08 & 0.04 & 0.00 & 0.01 & 0.01 & 0.00 & 0.04 & 0.02 & 0.01 & 0.01 & 0.05 & 0.06 & 0.17 & 0.07 & 0.20 & 0.27 \\
\hline Age & & & & 0.20 & 0.02 & 0.02 & 0.18 & 0.07 & 0.08 & 0.10 & 0.01 & 0.04 & & 0.29 & & \\
\hline Age + Woody Veg & & & 0.15 & 0.21 & 0.02 & & 0.23 & 0.10 & & 0.11 & 0.07 & 0.10 & 0.36 & 0.31 & & \\
\hline Area + Age & 0.14 & & & & 0.04 & & 0.19 & 0.13 & 0.10 & 0.14 & & 0.08 & & & & 0.27 \\
\hline TWI & & 0.04 & & & 0.01 & 0.00 & & 0.06 & 0.09 & & 0.03 & 0.03 & & & & \\
\hline Age + TWI & & & & 0.21 & 0.02 & & 0.20 & 0.11 & 0.14 & 0.13 & & & & 0.31 & & \\
\hline Age + Woody Veg + TWI & & & & & & & 0.26 & 0.16 & & 0.16 & 0.11 & 0.15 & 0.40 & 0.35 & & \\
\hline Woody Veg & & 0.04 & 0.09 & & 0.00 & 0.00 & & & & & 0.05 & 0.06 & & & & \\
\hline Area + TWI & & 0.10 & & & & & & 0.10 & & & 0.10 & 0.12 & & & 0.21 & 0.28 \\
\hline Area + Woody Veg & 0.15 & 0.12 & & & & & & & & & 0.08 & 0.09 & & & 0.21 & \\
\hline Woody Veg + TWI & & & 0.11 & & & & & 0.11 & & & 0.10 & 0.12 & & & & \\
\hline Area + Age + Woody Veg & 0.22 & & 0.16 & & & & & & & 0.18 & & & 0.40 & & & \\
\hline Area + Age + TWI & & & & & & & & 0.14 & 0.15 & 0.16 & & 0.13 & & & & \\
\hline
\end{tabular}


Area + Woody Veg + TWI

0.16

Area $+\mathrm{HCS}$

Age $+\mathrm{HCS}$

Age + HCS + Woody Veg

Area + Age + Woody Veg + TWI

HCS

Area + HCS + Woody Veg

Age $+\mathrm{HCS}+\mathrm{TWI}$

HCS + Woody Veg

HCS + TWI

HCS + Woody Veg + TWI

Area + Age + HCS + Woody Veg

Age + HCS + Woody Veg + TWI

Area + Age + HCS + Woody Veg + TWI

Area + Age $+\mathrm{HCS}^{\mathrm{d}}$

Area + Age + Woody Veg ${ }^{d}$

Area $+\mathrm{HCS}+\mathrm{TWI}^{\mathrm{d}}$

Area + Age $+\mathrm{HCS}+$ TWI $^{\mathrm{d}}$

$0.20 \quad 0.17$

0.23
0.18

0.14

0.17

0.03

$0.03 \quad 0.20 \quad 0.12$

$0.23 \quad 0.10$

0.20

$0.18 \quad 0.43$

$0.00 \quad 0.02$

$0.15 \quad 0.16$

0.12

0.13

0.11

0.14 
${ }^{a}$ delta Akaike Information Criterion adjusted for small sample size. ${ }^{\mathrm{b}}$ Spatial autocovariate included in all alternative models. ${ }^{\mathrm{c}}$ Null model. Values in italics indicate that the model was not within the top-ranked model set. ${ }^{\mathrm{d}}$ Not a top-ranked model. 


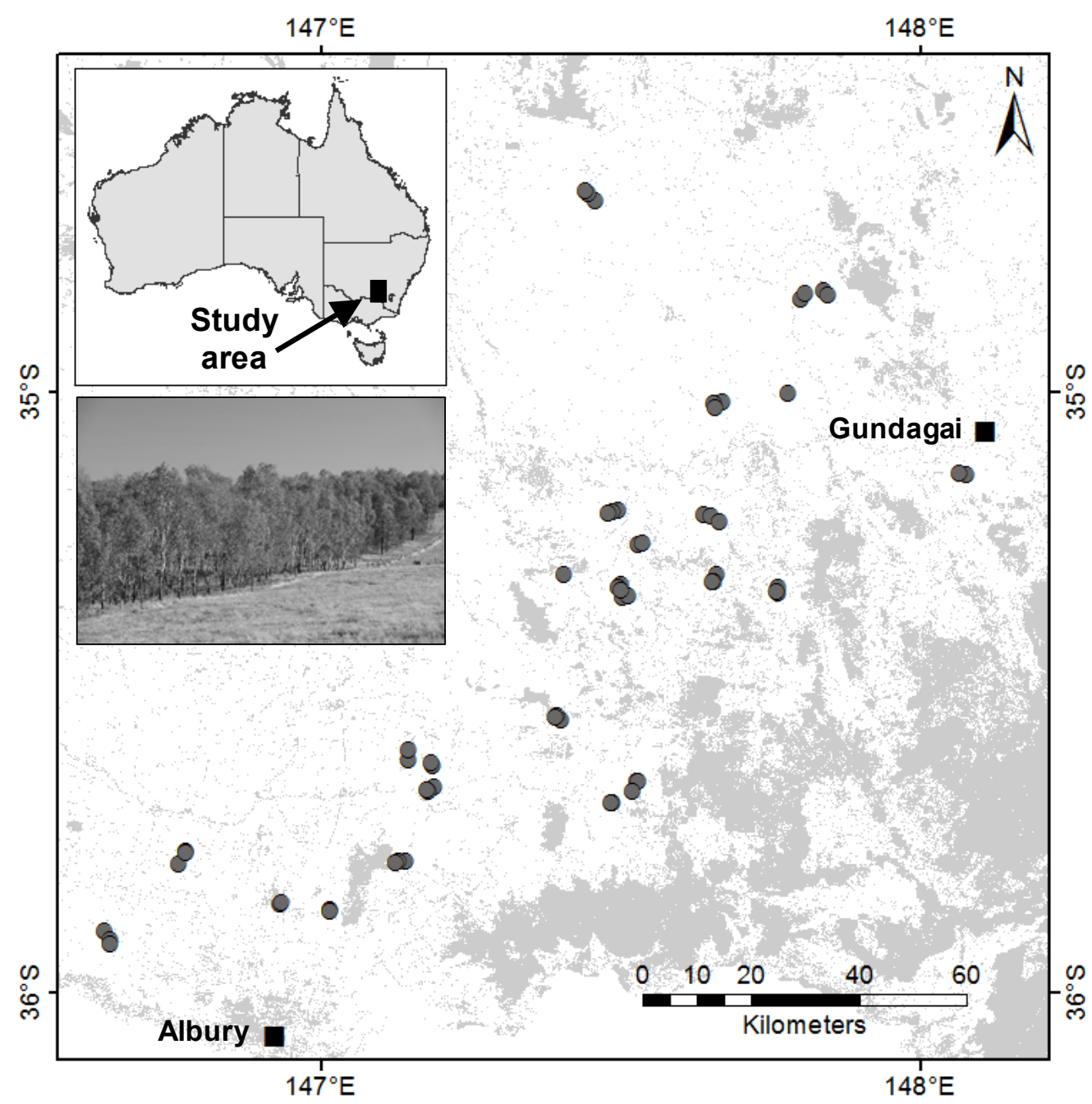

Figure 1: Map of study area showing restoration planting sites (note that points are not drawn to scale). Grey shading shows native woody vegetation cover. Insets show location of study area within Australia (top) and image of a typical planting site (bottom). Image by D. Blair. 
(a)

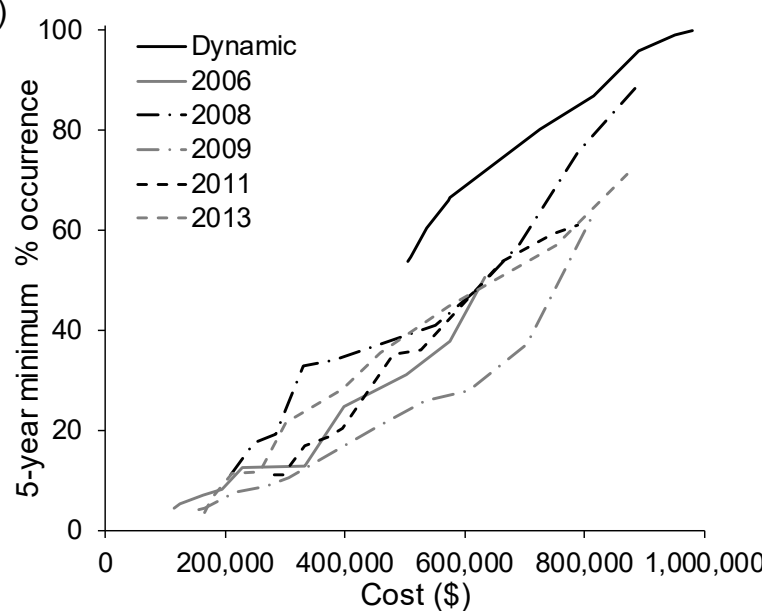

(b)

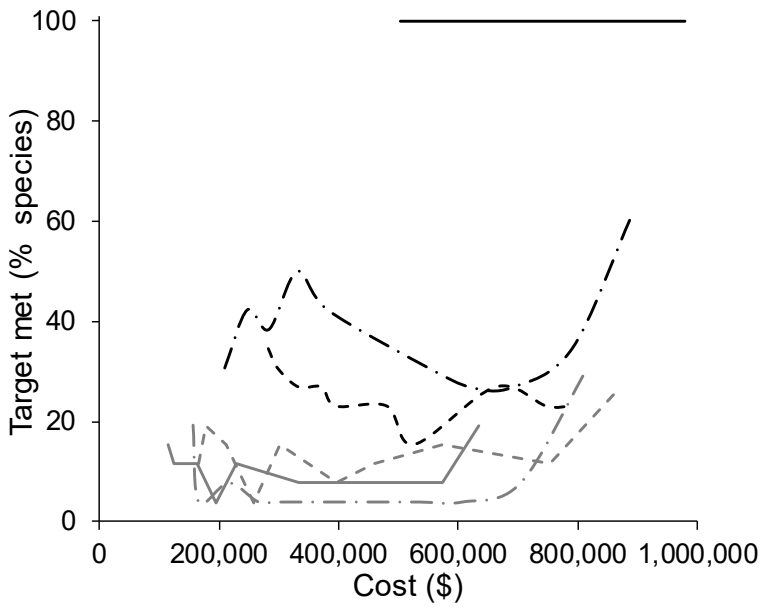

Figure 2. Comparison of five-year outcomes under dynamic and static complementarity approaches for (a) 5year mean minimum percent occurrence, and (b) targets met. Each line represents $10 \%$ to $100 \%$ representation targets. 
(a)

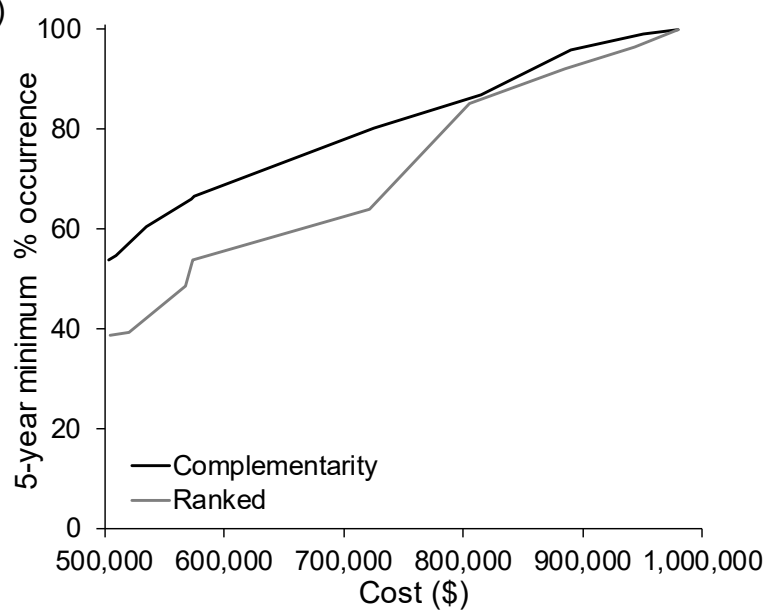

(b)

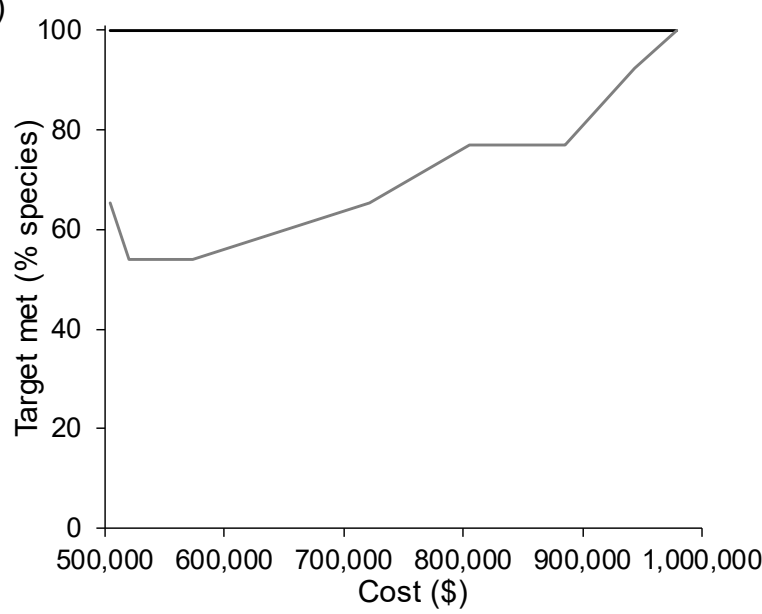

Figure 3: Comparison of dynamic complementarity and ranked approaches to maximise landscape-scale occurrence of species of conservation concern for (a) 5-year mean minimum percent occurrence, and (b) targets met. Each line represents $10 \%$ to $100 \%$ representation targets. 
(a) 2006 only

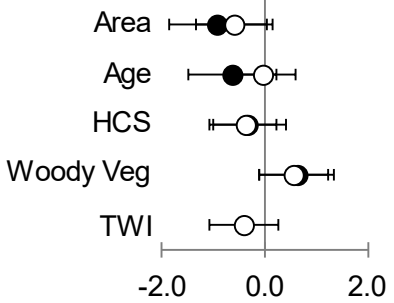

(c) Dynamic

Area

Age

HCS

Woody Veg

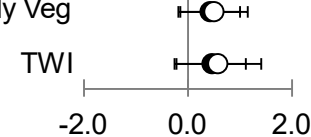

(e) Ranked

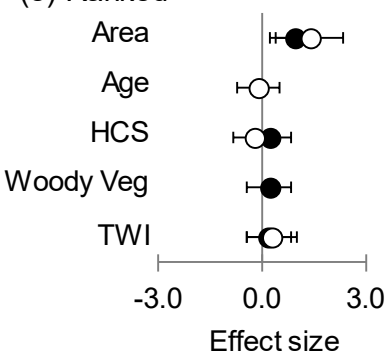

(b) 2013 only

HO
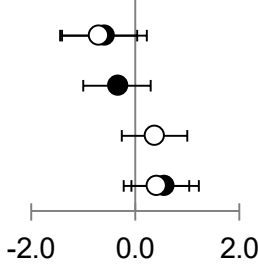

(d) Frequency

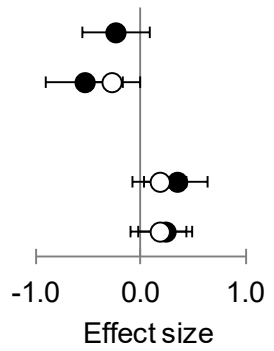

Figure 4: Summary of model-averaged effect sizes (and 95\% confidence intervals) for terms in the top-ranked models $(\triangle \mathrm{AICc} \leq 2)$ for $30 \%$ (closed circles) and $60 \%$ (open circles) representation targets. See Table 2 for a description of model terms. See Figure S1 for plots for 2008 only, 2009 only and 2011 only models. 


\section{Supporting Information}

Table S1: Summary of explanatory variables considered in the analyses, and example of a previous study that has found the variable to be important in explaining bird diversity in restoration plantings.

\begin{tabular}{|c|c|c|c|}
\hline Variable & Definition & Mean (Range) & Example studies \\
\hline Cost & Establishment cost & $\begin{array}{l}\$ 16,052 \\
(\$ 4,948- \\
\$ 75,869)\end{array}$ & Polyakov et al. 2015 \\
\hline Age & $\begin{array}{l}\text { Number of years since the establishment of the } \\
\text { planting (since 2006). }\end{array}$ & $11(0-44)$ & $\begin{array}{l}\text { Lindenmayer et al. } 2010 \\
\text { Munro et al. } 2011\end{array}$ \\
\hline Area & Size of planting (ha). & $\begin{array}{l}4.24(0.3- \\
60.3)\end{array}$ & $\begin{array}{l}\text { Kavanagh et al. } 2007 \\
\text { Lindenmayer et al. } 2010 \\
\text { Munro et al. } 2011\end{array}$ \\
\hline Width & Width of planting (m). & $\begin{array}{l}65.16(10- \\
300)\end{array}$ & $\begin{array}{l}\text { Kinross } 2004 \\
\text { Lindenmayer et al. } 2007 \\
\text { Lindenmayer et al. } 2010 \\
\text { Munro et al. } 2011\end{array}$ \\
\hline $\begin{array}{l}\text { Habitat } \\
\text { complexity } \\
\text { score (HCS) }\end{array}$ & $\begin{array}{l}\text { Vegetation structural complexity was based on } \\
\text { vegetation data collected in } 2007 / 08 \text { and } 2013 \text { : } \\
\text { (i) the percent cover of overstorey, midstorey } \\
\text { and understorey vegetation, the number of logs } \\
\text { per ha, and the presence of large trees ( }>50 \mathrm{~cm} \\
\text { diameter at breast height) were recorded within } \\
\text { three } 20 \text { x } 20 \mathrm{~m} \text { plots located at the } 0 \mathrm{~m}, 100 \mathrm{~m} \\
\text { and } 200 \mathrm{~m} \text { transect points; and (ii) the percent } \\
\text { cover of native grass, exotic grass, exotic } \\
\text { perennials, broadleaf weeds, forbs, leaf litter, } \\
\text { and moss and lichen were recorded within } \\
\text { twelve } 1 \mathrm{~m} \text { x } 1 \text { m quadrats located at the } \\
\text { corners of the plots. A combined site-level } \\
\text { habitat complexity score was calculated from } \\
\text { these data, following Munro et al. (2011) } \\
\text { (Table S2). }\end{array}$ & $18(9-29)$ & $\begin{array}{l}\text { Lindenmayer et al. } 2010 \\
\text { Munro et al. } 2011\end{array}$ \\
\hline $\begin{array}{l}\text { Woody } \\
\text { vegetation } \\
\text { (WoodyVeg) }\end{array}$ & $\begin{array}{l}\text { Percentage of vegetation cover within a } 1 \mathrm{~km} \\
\text { buffer from the } 100 \mathrm{~m} \text { transect point. Derived }\end{array}$ & $\begin{array}{l}5.45 \%(0.00 \% \\
-23.00 \%)\end{array}$ & $\begin{array}{l}\text { Kavanagh et al. } 2007 \\
\text { Lindenmayer et al. } 2010 \\
\text { Munro et al. } 2011\end{array}$ \\
\hline
\end{tabular}




\begin{tabular}{llll}
\hline Variable & Definition & Mean (Range) & Example studies \\
\hline & from Landsat satellite imagery (Danaher & & Radford et al. 2005 \\
& $2011)$. & & \\
Topographic & Position in landscape, ranging from ridge tops & $0.61(-2.68-$ & Lindenmayer et al. 2010 \\
wetness & to valley floors. Derived from a 20 m & $10.23)$ & Montague-Drake et al. \\
index (TWI) & resolution Digital Elevation Model (DEM) & & 2011 \\
& (Montague-Drake et al. 2011), and calculated & & \\
& at the 100 m transect point & & \\
&
\end{tabular}

\section{Literature cited}

Danaher, T. 2011. Description of remote sensing based Foliage Projective Cover and Woody Extent Products. Office of Environment and Heritage, NSW Department of Premier and Cabinet.

Kavanagh, R., M. A. Stanton, and M. W. Herring. 2007. Eucalypt plantings on farms benefit woodland birds in south-eastern Australia. Austral Ecol 32:635-650.

Kinross, C. 2004. Avian use of farm habitats, including windbreaks, on the New South Wales Tablelands. Pac Conserv Biol 10:180-192.

Montague-Drake, R. M., D. B. Lindenmayer, R. B. Cunningham, and J. A. Stein. 2011. A reverse keystone species affects the landscape distribution of woodland avifauna: A case study using the Noisy Miner (Manorina melanocephala) and other Australian birds. Landsc Ecol 26:1383-1394.

Lindenmayer, D. B., R. Cunningham, M. Crane, D. Michael, and R. Montague-Drake. 2007. Farmland bird responses to intersecting replanted areas. Landsc Ecol 22:1555-1562.

Lindenmayer, D. B., E. J. Knight, M. J. Crane, R. Montague-Drake, D. R. Michael, and C. I. MacGregor. 2010. What makes an effective restoration planting for woodland birds? Biol Conserv 143:289-301.

Munro, N., J. Fischer, G. Barrett, J. Wood, A. Leavesley, and D. B. Lindenmayer. 2011. Bird's response to revegetation of different structure and floristics - are "restoration plantings" restoring bird communities. Restor Ecol 19:223-235.

Polyakov, M., D. J. Pannell, M. Chalak, G. Park, A. Roberts, and A. D. Rowles. 2015. Restoring native vegetation in an agricultural landscape: spatial optimization for woodland birds. Land Economics 91:252-271.

Radford, J. Q., A. F. Bennett, and G. J. Cheers. 2005. Landscape-level thresholds of habitat cover for woodland-dependent birds. Biol Conserv 124:317-337. 
Table S2: Habitat complexity score (HCS). Planting HCS was the sum of the scores for each element.

\begin{tabular}{lccc}
\hline Score & Strata $\%$ cover* & Logs/ha & Trees $>50 \mathrm{~cm} / \mathrm{ha}$ \\
\hline 0 & $<1 \%$ & $<1$ & $<1$ \\
1 & $1-5 \%$ & $1-10$ & \\
2 & $6-30 \%$ & $11-50$ & \\
3 & $31-70 \%$ & $51-100$ & \\
4 & $>70 \%$ & $>100$ & $\geq 1$
\end{tabular}

*Strata includes overstorey, midstorey, understorey and ground layer (native tussock, exotic tussock, exotic grass, broadleaf weeds, forbs, and leaf litter).

Table S3: Costs of materials and labour for fencing and direct-seeding of restoration sites

\begin{tabular}{lll}
\hline Item & Description & Rate $(\$ A U D)$ \\
\hline Fencing & Fencing materials and labour & $\$ 10,000 / \mathrm{km}$ \\
Direct-seeding - materials & Seed, machinery & $<2 \mathrm{ha}=\$ 750 / \mathrm{ha}$ \\
& & $2-4 \mathrm{ha}=\$ 625 / \mathrm{ha}$ \\
& & $>4 \mathrm{ha}=\$ 550 / \mathrm{ha}$ \\
Direct-seeding - labour & Labour, site preparation & $\$ 77.68 / \mathrm{ha}$ \\
\hline
\end{tabular}


Table S4: Woodland bird species of conservation concern, justification for inclusion and number of observations between 2006 and 2013. 'Legislation': listed as threatened in NSW under the Threatened Species Conservation Act 1995 (this also captures relevant nationally-listed threatened species) and/or 'Atlas': identified as having a $>20 \%$ decrease in South West Slopes bioregion reporting rate between the first and second Atlas of Australian Birds.

\begin{tabular}{lllc}
\hline Common name & Scientific name & Source & Records \\
\hline Black-chinned Honeyeater & Melithreptus gularis & Legislation & 6 \\
Brown Songlark & Cincloramphus cruralis & Atlas & 56 \\
Brown Treecreeper & Climacteris picumnus & Legislation & 8 \\
Cockatiel & Nymphicus hollandicus & Atlas & 15 \\
Crested Shrike-tit & Falcunculus frontatus & Atlas & 30 \\
Diamond Firetail & Stagonopleura guttata & Legislation & 21 \\
Dollarbird & Eurystomus orientalis & Atlas & 2 \\
Dusky Woodswallow & Artamus cyanopterus & Atlas & 10 \\
Fairy Martin & Petrochelidon ariel & Atlas & 5 \\
Grey-crowned Babbler & Pomatostomus temporalis & Legislation & 11 \\
Jacky Winter & Microeca fascinans & Atlas & 3 \\
Little Lorikeet & Glossopsitta pusilla & Legislation & 3 \\
Masked Woodswallow & Artamus personatus & Atlas & 7 \\
Pied Butcherbird & Cracticus nigrogularis & Atlas & 5 \\
Rainbow Bee-eater & Merops ornatus & Atlas & 13 \\
Restless Flycatcher & Myiagra inquieta & Atlas & 9 \\
Scarlet Robin & Petroica boodang & Legislation & 2 \\
Southern Whiteface & Aphelocephala leucopsis & Atlas & 10 \\
Speckled Warbler & Chthonicola sagittata & Legislation & 9 \\
Superb Parrot & Polytelis swainsonii & Legislation & 19 \\
Weebill & Smicrornis brevirostris & Atlas & 66 \\
White-browed Woodswallow & Artamus superciliosus & Atlas & 54 \\
White-fronted Chat & Epthianura albifrons & Legislation & 8 \\
White-winged Triller & Lalage sueurii & Atlas & 46 \\
Yellow-rumped Thornbill & Acanthiza chrysorrhoa & Atlas & 119 \\
Zebra Finch & Taeniopygia guttata & Atlas & 2 \\
\hline
\end{tabular}


Table S5 Comparison of scenarios with cost included and excluded, for the $30 \%$ and $60 \%$ species occurrence targets. The locations of plantings selected under the two scenarios were similar (Bray-Curtis dissimilarity $13 \%$ and $23 \%$ for the $30 \%$ target and $60 \%$ target, respectively).

\begin{tabular}{lccccc}
\hline Scenario & Cost & Plantings & Area (ha) & \% Occurrence & Target met \\
\hline $30 \%$ : cost included & $\$ 535,125.80$ & 32 & 185.00 & 60.63 & 100 \\
$30 \%$ : cost excluded & $\$ 591,778.60$ & 30 & 203.80 & 60.28 & 100 \\
$60 \%$ : cost included & $\$ 725,628.00$ & 43 & 222.20 & 80.19 & 100 \\
$60 \%$ : cost excluded & $\$ 754,132.20$ & 42 & 227.50 & 80.53 & 100 \\
\hline
\end{tabular}

Table S6. Mean (SD) selection frequencies of plantings selected in the best solutions for each representation target and those not selected.

\begin{tabular}{ccc}
\hline & \multicolumn{2}{c}{ Best solution } \\
Target & Selected & Not selected \\
\hline $10 \%$ & $98.71(6.42)$ & $1.06(5.92)$ \\
$20 \%$ & $96.34(13.32)$ & $3.22(9.90)$ \\
$30 \%$ & $96.88(10.93)$ & $3.55(10.92)$ \\
$40 \%$ & $98.00(7.91)$ & $3.07(19.93)$ \\
$50 \%$ & $98.06(7.80)$ & $3.19(9.03)$ \\
$60 \%$ & $98.21(7.56)$ & $4.28(11.40)$ \\
$70 \%$ & $96.25(12.42)$ & $13.92(17.29)$ \\
$80 \%$ & $97.22(11.57)$ & $24.00(21.76)$ \\
$90 \%$ & $99.62(2.89)$ & $19.67(15.31)$ \\
$100 \%$ & $100.00(0.00)$ & - \\
\hline
\end{tabular}


Table S7. Summary of dynamic and static complementarity scenarios

\begin{tabular}{|c|c|c|c|c|c|c|c|c|c|c|c|c|c|c|c|c|c|c|}
\hline 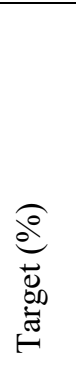 & 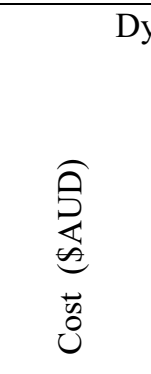 & 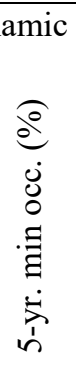 & 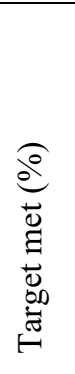 & 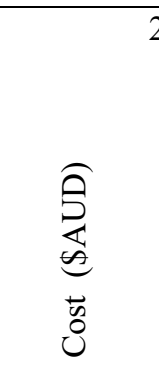 & 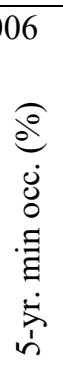 & 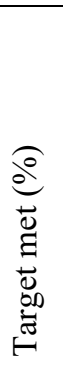 & 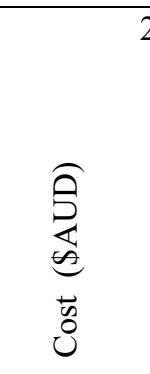 & 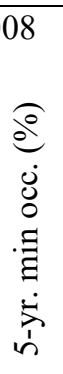 & 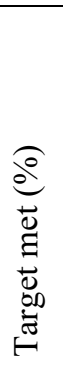 & 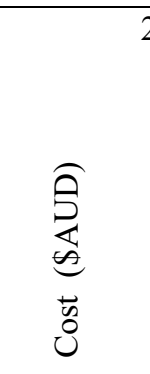 & 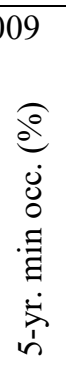 & 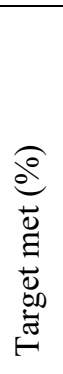 & 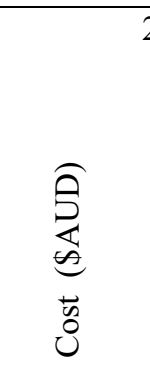 & 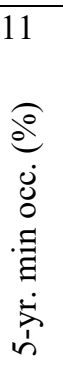 & 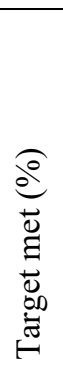 & 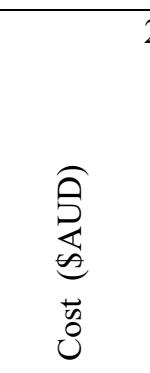 & $\begin{array}{l}\widehat{0} \\
\dot{0} \\
\dot{0} \\
0 \\
. \Xi \\
\vdots \\
\dot{1} \\
\dot{1}\end{array}$ & 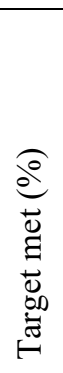 \\
\hline 10 & $\$ 503,891$ & 54 & 100 & $\$ 114,068$ & 5 & 15 & $\$ 209,546$ & 11 & 31 & $\$ 156,488$ & 4 & 19 & $\$ 281,986$ & 11 & 35 & $\$ 166,364$ & 4 & 12 \\
\hline 20 & $\$ 509,593$ & 55 & 100 & $\$ 123,890$ & 5 & 12 & $\$ 247,124$ & 17 & 42 & $\$ 166,002$ & 5 & 4 & $\$ 297,123$ & 11 & 31 & $\$ 177,061$ & 6 & 19 \\
\hline 30 & $\$ 535,126$ & 61 & 100 & $\$ 163,907$ & 7 & 12 & $\$ 283,631$ & 19 & 38 & $\$ 216,123$ & 8 & 8 & $\$ 332,201$ & 17 & 27 & $\$ 212,421$ & 11 & 15 \\
\hline 40 & $\$ 573,122$ & 66 & 100 & $\$ 195,243$ & 8 & 4 & $\$ 330,638$ & 33 & 50 & $\$ 266,335$ & 9 & 4 & $\$ 370,808$ & 19 & 27 & $\$ 257,570$ & 12 & 4 \\
\hline 50 & $\$ 575,591$ & 66 & 100 & $\$ 229,085$ & 13 & 12 & $\$ 381,571$ & 34 & 42 & $\$ 305,878$ & 10 & 4 & $\$ 395,025$ & 20 & 23 & $\$ 300,573$ & 22 & 15 \\
\hline 60 & $\$ 725,628$ & 80 & 100 & $\$ 332,518$ & 13 & 8 & $\$ 549,920$ & 41 & 31 & $\$ 448,961$ & 21 & 4 & $\$ 480,195$ & 35 & 23 & $\$ 395,403$ & 28 & 8 \\
\hline 70 & $\$ 814,979$ & 87 & 100 & $\$ 397,461$ & 25 & 8 & $\$ 620,428$ & 48 & 27 & $\$ 534,510$ & 26 & 4 & $\$ 525,713$ & 36 & 15 & $\$ 459,828$ & 36 & 12 \\
\hline 80 & $\$ 889,818$ & 96 & 100 & $\$ 503,252$ & 31 & 8 & $\$ 690,304$ & 57 & 27 & $\$ 606,834$ & 28 & 4 & $\$ 661,279$ & 54 & 27 & $\$ 572,794$ & 45 & 15 \\
\hline 90 & $\$ 951,035$ & 99 & 100 & $\$ 574,287$ & 38 & 8 & $\$ 789,620$ & 76 & 35 & $\$ 704,481$ & 37 & 8 & $\$ 746,849$ & 59 & 23 & $\$ 751,666$ & 57 & 12 \\
\hline 100 & $\$ 979,198$ & 100 & 100 & $\$ 633,418$ & 51 & 19 & $\$ 890,734$ & 89 & 62 & $\$ 816,398$ & 64 & 31 & $\$ 788,795$ & 61 & 23 & $\$ 870,880$ & 71 & 27 \\
\hline
\end{tabular}


Table S8. Summary of dynamic complementarity and ranked scenarios.

\begin{tabular}{|c|c|c|c|c|c|c|c|c|c|}
\hline 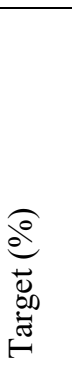 & 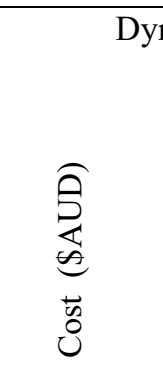 & 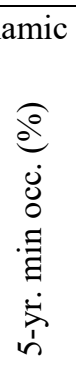 & 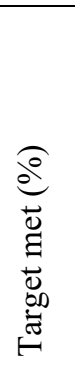 & 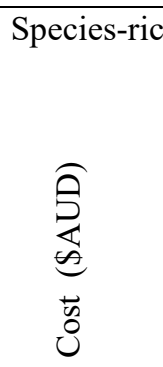 & 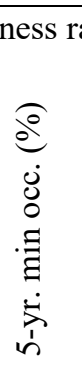 & 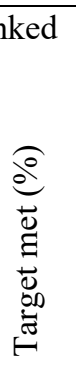 & 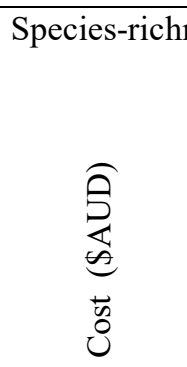 & $\begin{array}{l}\text { / cost } \\
\text { } \\
\stackrel{0}{0} \\
\dot{0} \\
0 \\
\dot{\Xi} \\
\dot{\Xi} \\
\dot{5} \\
\dot{1}\end{array}$ & 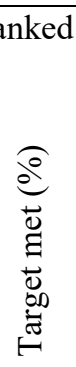 \\
\hline 10 & $\$ 503,891$ & 54 & 100 & $\$ 504,144$ & 39 & 65 & $\$ 502,903$ & 51 & 77 \\
\hline 20 & $\$ 509,593$ & 55 & 100 & $\$ 504,144$ & 39 & 65 & $\$ 502,903$ & 51 & 77 \\
\hline 30 & $\$ 535,126$ & 61 & 100 & $\$ 520,595$ & 39 & 54 & $\$ 525,424$ & 51 & 73 \\
\hline 40 & $\$ 573,122$ & 66 & 100 & $\$ 567,577$ & 49 & 54 & $\$ 565,378$ & 55 & 81 \\
\hline 50 & $\$ 575,591$ & 66 & 100 & $\$ 574,061$ & 54 & 54 & $\$ 565,378$ & 55 & 81 \\
\hline 60 & $\$ 725,628$ & 80 & 100 & $\$ 721,545$ & 64 & 65 & $\$ 701,886$ & 73 & 69 \\
\hline 70 & $\$ 814,979$ & 87 & 100 & $\$ 805,461$ & 85 & 77 & $\$ 819,627$ & 86 & 81 \\
\hline 80 & $\$ 889,818$ & 96 & 100 & $\$ 885,168$ & 92 & 77 & $\$ 865,478$ & 91 & 88 \\
\hline 90 & $\$ 951,035$ & 99 & 100 & $\$ 943,044$ & 96 & 92 & $\$ 892,227$ & 91 & 85 \\
\hline 100 & $\$ 979,198$ & 100 & 100 & $\$ 979,198$ & 100 & 100 & $\$ 979,198$ & 100 & 100 \\
\hline
\end{tabular}



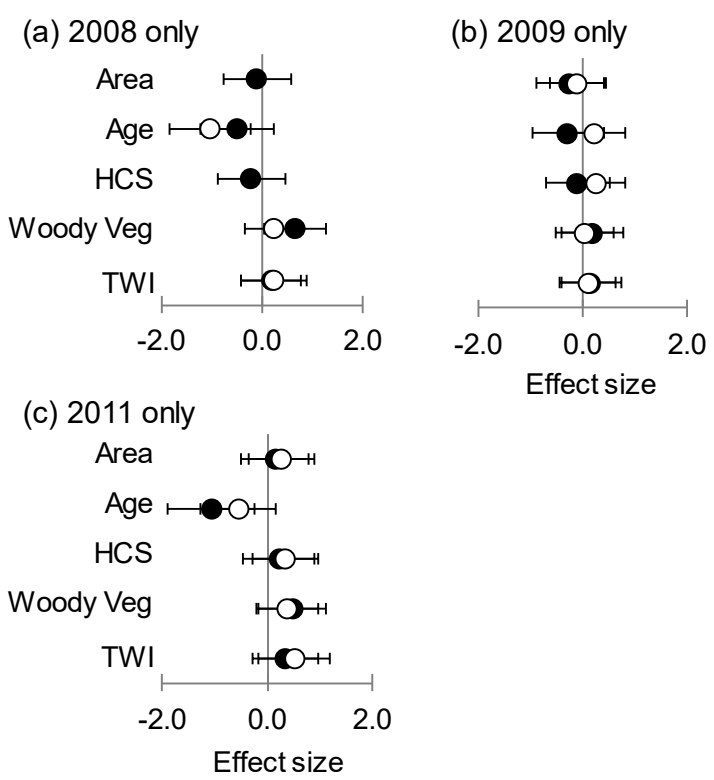

Figure S1. Summary of model-averaged effect sizes (and 95\% confidence intervals) for terms in the topranked models $(\triangle \mathrm{AICc} \leq 2)$ for $30 \%$ (closed circles) and $60 \%$ (open circles) representation targets. 'Area' is planting area, 'Age' is years since planting establishment, 'HCS' (habitat complexity score) represents vegetation structural complexity, 'Woody Veg' is percentage of vegetation cover within $1000 \mathrm{~m}$, and 'TWI' (topographic wetness index) represents position in landscape ranging from ridges to valley floors. See Table S1 for a full description of model terms. 